\title{
Immunomodulatory drug and dexamethasone- containing triple versus doublet combination treatments for relapsed or refractory multiple myeloma: a meta-analysis of phase III randomized controlled trials
}

\section{Minjie Gao}

Ningbo First Hospital

Xiao Yan

Ningbo First Hospital

Fei Li

First Affiliated Hospital of Nanchang University

Kaihong Xu

Ningbo First Hospital

Qitian Mu

Ningbo First Hospital

Lixia Sheng

Ningbo First Hospital

Yi Wang

Ningbo First Hospital

Van S. Tompkins

lowa State University

Guifang Ouyang ( $\nabla$ nbhematology@163.com )

Ningbo First Hospital https://orcid.org/0000-0002-3411-3666

Primary research

Keywords: multiple myeloma, relapsed, refractory, immunomodulatory, meta-analysis, dexamethasone

Posted Date: August 12th, 2020

DOI: https://doi.org/10.21203/rs.3.rs-55347/v1

License: (c) (1) This work is licensed under a Creative Commons Attribution 4.0 International License.

Read Full License 


\section{Abstract \\ Background}

Triplet therapy has become the standard of care for relapsed or refractory multiple myeloma (RRMM) over the past few years. Prior to that, doublet therapy including dexamethasone and an immunomodulatory were standard. Several systematic studies have been conducted and many combinations with variable triplet therapies but have not always used the former standard therapy as a benchmark. The objective of this meta-analysis was to evaluate the efficacy and safety of triplet combinations that included dexamethasone and an immunomodulatory drug versus a doublet combination of just dexamethasone and an immunomodulatory for the treatment of RRMM.

\section{Methods}

A comprehensive literature search (PubMed, EMBASE, Cochrane Library) for phase III randomized controlled trials for efficacy and safety of triplet versus doublet combinations that specifically included dexamethasone and an immunomodulatory drug for treatment of RRMM. Efficacy (ORR, PFS, OS) and adverse events ( $\geq$ grade 3 ) were assessed using traditional statistical measures for aggregate data.

\section{Results}

Of 235 potential reports, 6 met the inclusion criteria ( $N=115-792$ participants). The methodological quality was $\geq 4$ Jadad score for each. Triplet treatment had higher ORR (HR $=0.74,95 \% \mathrm{Cl}: 0.65-0.84, \mathrm{P}$ $\leq 0.001)$, PFS (HR=0.63, 95\%Cl: $0.52-0.75, \mathrm{P} \leq 0.001)$, and OS ( $\mathrm{HR}=0.74,95 \% \mathrm{Cl}: 0.65-0.84, \mathrm{P} \leq 0.001)$. The incidence of $\geq$ grade 3 diarrhea and fatigue were significantly higher in the triplet combination group. There was a trend toward increased incidence of $\geq$ grade 3 neutropenia, thrombocytopenia, thromboembolism, and peripheral neuropathy in the triplet therapy group. Notably, triplet therapy had a significantly lower rate of anemia compared to doublet therapy.

\section{Conclusions}

This study reinforces current guidelines and recommendations for triplet combinations containing dexamethasone and an immunomodulatory drug.

\section{Introduction}

Multiple myeloma (MM), a malignant disease of monoclonal plasma cells, accounts for approximately $10 \%$ of hematologic cancers $(1)$ and is the second most common hematologic malignancy $(2,3)$. The introduction of agents such as immunomodulatory drugs, proteasome inhibitors, and monoclonal antibodies have improved treatment outcomes (4-7). Patients with MM often respond to initial therapy 
but ultimately relapse and become refractory to further treatment, underscoring the need for new therapeutic approaches for these patients (8-10). The addition of immunomodulatory drugs (eg, thalidomide, lenalidomide, and pomalidomide) to dexamethasone showed clinical benefits in this patient population (11-13). Unfortunately, the prognosis of patients with relapsed or refractory disease remained poor.

As other agents were developed (eg bortezomib, carfilzomib, ixazomib, elotuzumab, or daratumumab), the question arose as to whether triplet regimens - combinations of these or dexamethasone or immunomodulatory agents - exhibited better progression-free survival (PFS) and overall survival (OS) with acceptable side-effect profiles compared with the prior standard doublet regimen. Several randomized controlled trials (RCTs) have been conducted to investigate this in relapsed or refractory MM (RRMM), but the results have been controversial (14-19). Attempting to collate this information, Sun et al. (2017), Botta et al. (2017), van Beurden-Tan et al. (2017), and Dimopoulus et al. (2018) have each performed meta-analyses of triplet versus doublet therapy regimen RCTs for RRMM patients, but none of these studies focused specifically on dexamethasone with an immunomodulatory drug (20-23). Therefore, we conducted this meta-analysis to compare the efficacy and safety of triplet combinations that included dexamethasone and an immunomodulatory agent versus the former standard of care doublet combination of dexamethasone and an immunomodulatory drug in patients with RRMM.

\section{Methods}

\section{Search strategy and study selection}

Clinical trials were included in this study if they met the following criteria: (1) study design: phase III RCTs to include both efficacy and safety comparisons to the standard; (2) study population: patients with RRMM; (3) acceptable comparisons: immunomodulatory drug and dexamethasone-containing triple combination versus doublet combination of immunomodulatory drug and dexamethasone; and (4) the study was required to evaluate both therapy efficacy and safety. The search strategy was as follows: databases, including PubMed, EMBASE, and the Cochrane Library, were searched by two reviewers (MjG and $X Y$ ) to identify pertinent studies using the following search terms: "multiple myeloma", "relapsed or refractory", and "prospective study or clinical trials". Other potentially relevant studies were also manually searched based on the reference lists from the trials identified. Language was restricted to English. If multiple publications of the same trial were retrieved, only the most complete data was included. Studies were excluded if they did not meet the inclusion criteria $(24,25)$. All data retrieved were updated to August 2019.

\section{Data extraction and methodological quality assessment}

Two independent data analysts ( $\mathrm{MjG}$ and $\mathrm{KhX}$ ) extracted trial details including author, study design, sample size, median age, and treatment regimens. Outcomes of interest were overall response rate (ORR), progression-free survival (PFS), overall survival (OS) and $\geq$ grade 3 toxicities. Any disagreements were resolved by consultation with a third analyst (LxS). Methodological quality of each trial was evaluated by 
two independent reviewers (MjG and $\mathrm{KhX}$ ) using the Jadad scale including randomization, doubleblinding, and withdrawal/dropout. The maximal score for an included study was 5 and studies were classified as high (score 3-5) or low (0-2) (26). Given the small numbers of trials included in this metaanalysis, publication bias was not formally assessed $(27,28)$.

\section{Statistical analysis}

Statistical analyses of the overall hazard ratio (HR) for survival data (OS, PFS) and the risk ratio (RR) for dichotomous outcomes (ORR, toxicities) were performed. Results are reported with $95 \%$ confidence intervals (Cls) on the test for overall effect. The main modality of presenting numerical data in visual

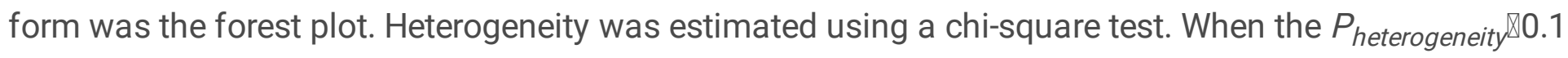
or the $\mathrm{I}^{2} \varangle 50 \%$, the heterogeneity was considered statistically significant (29). A fixed effect model was employed for outcomes without heterogeneity; a randomized effect model with inverse variance using a restricted maximum likelihood variance estimator was employed if heterogeneity was detected. Statistical significance was determined by $P \otimes 0.05$. All P-values were two-sided. All Cls had a two-sided probability coverage of $95 \%$. All analyses were performed in Stata 11.0 .

\section{Results}

\section{Search results}

The initial literature search yielded 235 potentially relevant studies, of which 218 were excluded after screening titles and abstracts. The full text of the remaining 17 studies were reviewed. Most of these were subsequently excluded $(n=11)$ for failing inclusion criteria, leaving a total of 6 studies (14-19) used in the meta-analysis. Figure 1 shows a diagram of the study selection process.

\section{Characteristics of the trials}

The trial results were published between 2012 and 2019 and had sample sizes ranging from 115 to 792 patients. The basic characteristics of the included studies are listed in Table 1 . Four trials $(14,15,17,19)$ investigated the role of the triple combination by adding a proteasome inhibitor to an immunomodulatory drug and dexamethasone, while another two trials $(16,18)$ added a monoclonal antibody. Among all six trials, five used lenalidomide(14-18), one used thalidomide(19), and none used pomalidomide. The patients in the two treatment groups had relatively similar ages across all six trials (14-19). The demographic and clinical characteristics of patients of each study are listed in Table 2. 
Characteristics of Phase III RCT studies included in the meta-analysis

\begin{tabular}{|c|c|c|c|c|}
\hline Author/year & & Treatment regimens & $\begin{array}{l}\text { No. of } \\
\text { patients }\end{array}$ & $\begin{array}{l}\text { Median age } \\
\text { (range) }\end{array}$ \\
\hline \multirow{2}{*}{$\begin{array}{l}\text { Dimopoulos et } \\
\text { al., } 2016\end{array}$} & Expt: & \multirow{2}{*}{$\begin{array}{l}\text { Daratumumab } 16 \mathrm{mg} / \mathrm{kg}+\mathrm{L} 25 \mathrm{mg}+\mathrm{D} \\
40 \mathrm{mg}\end{array}$} & 286 & $65(34-89)$ \\
\hline & Ctrl: & & 283 & $65(42-87)$ \\
\hline \multirow{2}{*}{$\begin{array}{l}\text { Moreau et al., } \\
2016\end{array}$} & Expt: & Ixazomib $4 \mathrm{mg}+\mathrm{L} 25 \mathrm{mg}+\mathrm{D} 40 \mathrm{mg}$ & 360 & $66(38-91)$ \\
\hline & Ctrl: & $P 4 \mathrm{mg}+\mathrm{L} 25 \mathrm{mg}+\mathrm{D} 40 \mathrm{mg}$ & 362 & $66(30-89)$ \\
\hline \multirow[t]{2}{*}{ Hou et al., 2017} & Expt: & Ixazomib $4 \mathrm{mg}+\mathrm{L} 25 \mathrm{mg}+\mathrm{D} 40 \mathrm{mg}$ & 57 & $61(30-76)$ \\
\hline & Ctrl: & $P 4 \mathrm{mg}+\mathrm{L} 25 \mathrm{mg}+\mathrm{D} 40 \mathrm{mg}$ & 58 & $62(36-80)$ \\
\hline \multirow{3}{*}{$\begin{array}{l}\text { Stewart et al., } \\
2015\end{array}$} & Expt: & \multirow{2}{*}{$\begin{array}{l}\text { Carfilzomib (intl } 20 \mathrm{mg} / \mathrm{m}^{2}, \text { maint } \\
\left.27 \mathrm{mg} / \mathrm{m}^{2}\right)+\mathrm{L} 25 \mathrm{mg}+\mathrm{D} 40 \mathrm{mg}\end{array}$} & 396 & $64(38-87)$ \\
\hline & Ctrl: & & \multirow[t]{2}{*}{396} & \multirow[t]{2}{*}{$65(31-91)$} \\
\hline & & L $25 \mathrm{mg}+\mathrm{D} 40 \mathrm{mg}$ & & \\
\hline \multirow{2}{*}{$\begin{array}{l}\text { Dimopoulos et } \\
\text { al., } 2017\end{array}$} & Expt: & Elotuzumab $10 \mathrm{mg} / \mathrm{kg}+\mathrm{L} 25 \mathrm{mg}+\mathrm{D} 40 \mathrm{mg}$ & 321 & $67(37-88)$ \\
\hline & Ctrl: & L $25 \mathrm{mg}+\mathrm{D} 40 \mathrm{mg}$ & 325 & $66(38-91)$ \\
\hline \multirow{3}{*}{$\begin{array}{l}\text { Garderet et al., } \\
2012\end{array}$} & Expt: & \multirow{2}{*}{$\begin{array}{l}\text { Bortezomib } 1.3 \mathrm{mg} / \mathrm{m}^{2}+\mathrm{T} 200 \mathrm{mg}+\mathrm{D} \\
40 \mathrm{mg}\end{array}$} & 134 & $60(29-76)$ \\
\hline & Ctrl: & & \multirow[t]{2}{*}{135} & \multirow[t]{2}{*}{$63(39-75)$} \\
\hline & & $\mathrm{T} 200 \mathrm{mg}+\mathrm{D} 40 \mathrm{mg}$ & & \\
\hline
\end{tabular}


Table 2

Patients' characteristics in included studies

\begin{tabular}{|c|c|c|c|c|c|c|}
\hline Study & $\begin{array}{l}\text { Dimopoulos } \\
\text { et al/2016 }\end{array}$ & $\begin{array}{l}\text { Moreau } \\
\text { et } \\
\text { al/2016 }\end{array}$ & $\begin{array}{l}\text { Hou et } \\
\text { al/2017 }\end{array}$ & $\begin{array}{l}\text { Stewart } \\
\text { et } \\
\text { al/2015 }\end{array}$ & $\begin{array}{l}\text { Dimopoulos } \\
\text { et al/2017 }\end{array}$ & $\begin{array}{l}\text { Garderet } \\
\text { et } \\
\text { al/2012 }\end{array}$ \\
\hline Age & 65 & 66 & 61 & 64 & 66 & 61 \\
\hline Median (yr) & 48 & 48 & 72 & 50 & NA & NA \\
\hline 『65 year (\%) & 52 & 52 & 28 & 50 & NA & NA \\
\hline \multicolumn{7}{|l|}{$\geq 65$ year $(\%)$} \\
\hline \multirow{2}{*}{$\begin{array}{l}\text { ECOG performance } \\
\text { status }(\%)\end{array}$} & 51 & 94 & 97 & 90.5 & NA & NA \\
\hline & 49 & 6 & 3 & 9.5 & NA & NA \\
\hline \multirow{2}{*}{$\begin{array}{l}\text { Cytogenetic profile } \\
(\%)\end{array}$} & 16 & 19 & NA & 12.6 & NA & NA \\
\hline & 84 & 57 & NA & 40 & NA & NA \\
\hline $\begin{array}{l}\text { High risk } \\
\text { Standard risk } \\
\text { unknown }\end{array}$ & 0 & 24 & NA & 47.3 & NA & NA \\
\hline $\begin{array}{l}\text { Previous regimens } \\
\text { (\%) }\end{array}$ & NA & 61 & 44 & 43 & 48 & NA \\
\hline 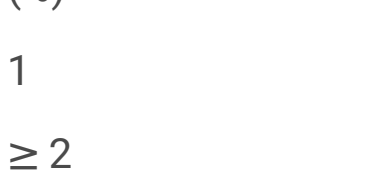 & NA & 39 & 56 & 57 & 52 & NA \\
\hline \multirow{2}{*}{$\begin{array}{l}\text { Previous therapies } \\
(\%)\end{array}$} & 55 & 57 & 86 & 20 & 54 & 8 \\
\hline & NA & 12 & 9 & 20 & 6 & 0 \\
\hline $\begin{array}{l}\text { Immunomodulatory } \\
\text { drugs }\end{array}$ & NA & 45 & 84 & 0 & 48 & 8 \\
\hline \multicolumn{7}{|l|}{ Lenalidomide } \\
\hline \multicolumn{7}{|l|}{ Thalidomide } \\
\hline \multirow{2}{*}{$\begin{array}{l}\text { ISS disease stage } \\
(\%)\end{array}$} & 49 & 64 & 60 & NA & 43 & 58 \\
\hline & 31 & 24 & 32 & NA & 32 & 26 \\
\hline . & 20 & 12 & 8 & NA & 21 & 16 \\
\hline II & 0 & 0 & 0 & NA & 4 & 0 \\
\hline \multicolumn{7}{|l|}{ Not reported } \\
\hline NA: not available & & & & & & \\
\hline
\end{tabular}




\begin{tabular}{|lllllll|}
\hline Study & $\begin{array}{l}\text { Dimopoulos } \\
\text { et al/2016 }\end{array}$ & $\begin{array}{l}\text { Moreau } \\
\text { et } \\
\text { al/2016 }\end{array}$ & $\begin{array}{l}\text { Hou et } \\
\text { al/2017 }\end{array}$ & $\begin{array}{l}\text { Stewart } \\
\text { et } \\
\text { al/2015 }\end{array}$ & $\begin{array}{l}\text { Dimopoulos } \\
\text { et al/2017 }\end{array}$ & $\begin{array}{l}\text { Garderet } \\
\text { et } \\
\text { al/2012 }\end{array}$ \\
\hline $\begin{array}{l}\text { Previous stem-cell } \\
\text { transplantation (\%) }\end{array}$ & 63 & 57 & 17 & NA & 54 & 100 \\
\hline NA: not available & & & & & & \\
\hline
\end{tabular}

The methodological quality of the included studies is summarized in Table 3. All six trials described acceptable methods of randomization. Two trials $(15,17)$ reported blinding of both the participants and outcome assessors. All six trials had clear descriptions of participant dropouts with acceptable dropout

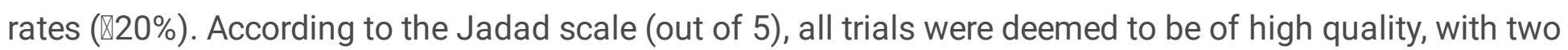
trials $(15,17)$ scoring 5 and the remaining four $(14,16,18,19)$ scoring 4 each.

Table 3

Methodological quality of included trials, assessed according to the Jadad scale

\begin{tabular}{|lllll|}
\hline Author [Year] & Randomization & Blinding & Withdrawal/lost to follow-up & Total \\
\hline Dimopoulos et al., 2016 & 2 & 1 & 1 & 4 \\
\hline Moreau et al., 2016 & 2 & 2 & 1 & 5 \\
\hline Hou et al., 2017 & 2 & 2 & 1 & 5 \\
\hline Stewart et al., 2015 & 2 & 1 & 1 & 4 \\
\hline Dimopoulos et al., 2017 & 2 & 1 & 1 & 4 \\
\hline Garderet et al., 2012 & 2 & 1 & 1 & 4 \\
\hline
\end{tabular}

\section{Overall survival}

Data of five trials $(14,16-19)$ was eligible for the analysis of OS. Using a fixed-effects model $\left(I^{2}=17.8 \%\right.$, $\left.P_{\text {heterogeneity }}=0.301\right)$, the pooled results indicated that triplet therapy significantly improved OS over doublet therapy with a HR of 0.74 (95\% Cl: $0.65-0.84, \mathrm{P} \leq 0.001$; Fig. 2).

\section{Progression-free survival}

Data on PFS was extracted from all the six trials (14-19). Using a random-effects model $\left(I^{2}=65.6 \%\right.$, $P_{\text {heterogeneity }}=0.013$ ), we observed that triplet therapy significantly improved PFS, with a HR of 0.63 (95\%Cl: 0.52-0.75, P $\leq 0.001$; Fig. 3) compared to doublet therapy.

\section{Overall response rate}

Data on ORR was available in all the six trials (14-19). Using a random-effects model $\left(I^{2}=58.0 \%\right.$, $\left.P_{\text {heterogeneity }}=0.036\right)$, the pooled results showed that there was a significant improvement for triplet 
therapy, with a RR of 1.21 (95\%Cl: $1.14-1.30, \mathrm{P} \leq 0.001$; Fig. 4).

\section{Safety}

All six trials (14-19) reported the incidence of $\geq$ grade 3 adverse events. As shown in Table 4 , there was a statistically significant increase in those having experienced $\geq$ grade 3 diarrhea $(\mathrm{RR}=1.44 ; 95 \% \mathrm{Cl}$ : $1.01-$ $2.05, P=0.045)$ and fatigue $(R R=1.38 ; 95 \% \mathrm{Cl}: 1.03-1.85, P=0.031)$ in the triplet therapy group. Though no statistically significant differences in $\geq$ grade 3 neutropenia $(R R=1.02 ; 95 \% \mathrm{Cl}: 0.81-1.29, P=0.846)$, thrombocytopenia $(\mathrm{RR}=1.34 ; 95 \% \mathrm{Cl}$ : 0.98-1.82, $\mathrm{P}=0.065)$, thromboembolism ( $\mathrm{RR}=1.23$; $95 \% \mathrm{Cl}$ : 0.85$1.79, P=0.263)$ or peripheral neuropathy $(R R=1.46 ; 95 \% \mathrm{Cl}: 0.98-2.18, P=0.063)$ were observed between the two treatment groups, the latter three show increases with triplet therapy. Notably, patients who had triplet therapy had a significantly lower rate of anemia than those who received doublet therapy $(R R=$ 0.83; 95\%Cl: 0.71-0.98, P = 0.03).

Table 4

Summary of $\geq$ grade 3 adverse events meta-analysis comparing triplet versus doublet therapy in RRMM

\begin{tabular}{|llllll|}
\hline$\geq$ grade 3 adverse events & No. of trials & $\mathbf{l}^{2}$ & $\mathbf{P}_{\text {heterogeneity }}$ & $\mathbf{R R}(\mathbf{9 5 \%} \mathrm{Cl})$ & $\boldsymbol{P}$ \\
\hline Anemia & 6 & $41.3 \%$ & 0.130 & $0.83(0.71-0.98)$ & 0.03 \\
\hline Neutropenia & 6 & $74.1 \%$ & 0.002 & $1.02(0.81-1.29)$ & 0.846 \\
\hline Thrombocytopenia & 6 & $64.7 \%$ & 0.015 & $1.34(0.98-1.82)$ & 0.065 \\
\hline Thromboembolism & 5 & $44.9 \%$ & 0.123 & $1.23(0.85-1.79)$ & 0.263 \\
\hline Peripheral neuropathy & 5 & $22.5 \%$ & 0.276 & $1.46(0.98-2.18)$ & 0.063 \\
\hline Fatigue & 6 & $0 \%$ & 0.527 & $1.38(1.03-1.85)$ & 0.031 \\
\hline Diarrhea & 5 & $11.6 \%$ & 0.34 & $1.44(1.01-2.05)$ & 0.045 \\
\hline
\end{tabular}

\section{Discussion}

Currently, management of $\mathrm{MM}$ remains challenging and relapse of $\mathrm{MM}$ and disease progression is common even after achievement of complete remission. With many novel agents available to treat RRMM patients, there is a need to identify the optimal combinations to achieve an appropriate balance between efficacy and safety. Immunomodulatory drugs in combination with dexamethasone have shown great clinical benefit in patients with $\operatorname{RRMM}(12,30)$. The main goal of this meta-analysis was to systematically analyze the efficacy and toxicity of triple combinations specifically containing dexamethasone and an immunomodulatory in treatment for RRMM. Our results suggested that triple combinations containing dexamethasone and an immunomodulatory significantly increased ORR and, importantly, improved PFS and OS, indicating a survival advantage with an added treatment agent. These findings are fully congruent with Dimopoulos et al. (2018) (23) who used a Bayesian approach to a meta- 
analysis and found that triplet therapies were superior to doublet therapies. The focus of that study was distinct in that they used immunomodulatory treatment in at least two arms within the same study as a criterion, whereas we focused on the combination of dexamethasone and an immunomodulatory. Using classical statistics, our study confirms their finding that adding a third agent (specifically daratumumab in their study) to an immunomodulatory and dexamethasone was most efficacious - an identical finding to that of both Botta et al. (2017) (21) and van Beurden-Tan et al. (2017) (22). Thus, our results are in line with current guidelines and treatment recommendations for RRMM.

Similar to Botta et al. (2017) (21), this study also assessed adverse effects, though their work compared bortezomib-containing versus immunomodulatory-containing regiments. With the focus on dexamethasone and an immunomodulatory, we found the incidence of $\geq$ grade 3 diarrhea and fatigue were significantly higher in the triplet combination group. There was a trend toward increased incidence of $\geq$ grade 3 neutropenia, thrombocytopenia, thromboembolism, and peripheral neuropathy in the triplet therapy group, but these did not reach statistical significance compared to doublet therapy. Cautious interpretation is advised here as these studies may have been under powered; thus, while more trials and patients are needed to determine whether the trends underly reality, it appears as though these adverse effects are more likely to be observed in patients on triplet therapies including dexamethasone and an immunomodulatory. Interestingly, we found that triplet therapy had a lower rate of anemia compared to doublet therapy. Anemia is a typical symptom of MM, so the lower rate of anemia may reflect better efficacy of the triplet therapy.

This meta-analysis had some limitations. The work was based on published studies, not an analysis of individual patient data, which limited time-to-event analyses. Our analysis was also limited to the available published data, which omits unpublished or ongoing trials and is subject to a reasonable risk of reporting bias. This study is underpowered for assessment of publication bias by current statistical approaches (31). Despite these limitations, our meta-analysis includes a comprehensive search for eligible studies, the careful consideration of study quality, and a rigorous analytical approach.

The focus on studies that included only dexamethasone and immunomodulatory drug treatments for comparisons allows for informed treatment decisions based on these two standard therapies. This last point is a key difference between this study and that of Sun et al. (2017). Sun et al. (2017) also included a report that compared treatments with bortezomib and dexamethasone along with studies that included treatments with immunomodulatory agents and dexamethasone(20). While survival outcomes were similar between the two studies, a clear difference was observed for one major adverse outcome: anemia. Our analysis suggests triplet therapy including an immunomodulatory and dexamethasone may reduce the occurrence of anemia over doublet therapy. This is the first meta-analysis of RCTs in patients with RRMM suggesting that triplet combinations that include dexamethasone and an immunomodulatory drug have a favorable risk-benefit profile compared with treatments that only include dexamethasone and an immunomodulatory drug. This is completely consistent with a recent report from Alahmadi et al. (2019), who found that adding cyclophosphamide to lenalidomide and dexamethasone had clinical benefit with manageable toxicities(32), and Attal et al.(2019), who found that adding isatuximab to 
pomalidomide and dexamethasone enhanced PFS(33). Given the high degree of variability of real patient populations and treatment outcomes in RRMM(34), our study provides additional evidence for clinicians as they consider whether immunomodulatory and dexamethasone-based combinations are the best treatment options for their patients.

\section{Abbreviations}

RRMM: relapsed or refractory multiple myeloma; PFS:progression-free survival; OS:overall survival; RCTs:randomized controlled trials; MM, multiple myeloma; HR, hazard ratio; RR, risk ratio.

\section{Declarations}

\section{Ethics approval and consent to participate}

Not applicable

Consent for publication

Not applicable

\section{Availability of data and materials}

All data used in this report were derived from the public domain and available as part of the original studies used for analyses.

\section{Competing interests}

The authors declare that they have no competing interests.

\section{Funding}

This review was supported by Grant from the Medical \& Health Technology Program of Zhejiang Province (no.2018KY678), the Natural Science Foundation of Ningbo, China (grant nos.2017A610177), the Natural Science Foundation of Zhejiang Province (nos.LY17H160005) and the Project from Traditional Chinese Medicine Administration of Zhejiang Province (no.2015ZZ018).

\section{Author contributions}

Minjie Gao, Yi Wang and Guifang Ouyang conceived and designed the study. Minjie Gao, Xiao Yan, Fei Li, Kaihong $\mathrm{Xu}$ and Lixiang Sheng collected and analyzed data. Minjie Gao and Qitian Mu drafted the manuscript. Van S. Tompkins and Guifang Ouyang revised the manuscript. All authors read and approved the final manuscript.

\section{Acknowledgments}


Not applicable.

\section{References}

1. Moreau P. How I treat myeloma with new agents. Blood. 2017;130(13):1507-13.

2. Anderson KC. Progress and Paradigms in Multiple Myeloma. Clinical cancer research: an official journal of the American Association for Cancer Research. 2016;22(22):5419-27.

3. Raab MS, Podar K, Breitkreutz I, Richardson PG, Anderson KC. Multiple myeloma. Lancet. 2009;374(9686):324-39.

4. Chim CS, Kumar SK, Orlowski RZ, Cook G, Richardson PG, Gertz MA, et al. Management of relapsed and refractory multiple myeloma: novel agents, antibodies, immunotherapies and beyond. Leukemia. 2017.

5. Dhakal B, Szabo A, Chhabra S, Hamadani M, D'Souza A, Usmani SZ, et al. Autologous Transplantation for Newly Diagnosed Multiple Myeloma in the Era of Novel Agent Induction: A Systematic Review and Meta-analysis. JAMA oncology. 2018.

6. Richardson PG, Kumar S, Laubach JP, Paba-Prada C, Gupta N, Berg D, et al. New developments in the management of relapsed/refractory multiple myeloma - the role of ixazomib. Journal of blood medicine. 2017;8:107-21.

7. Laubach JP, Paba Prada CE, Richardson PG, Longo DL. Daratumumab, Elotuzumab, and the Development of Therapeutic Monoclonal Antibodies in Multiple Myeloma. Clin Pharmacol Ther. 2017;101(1):81-8.

8. Chari A, Suvannasankha A, Fay JW, Arnulf B, Kaufman JL, Ifthikharuddin JJ, et al. Daratumumab plus pomalidomide and dexamethasone in relapsed and/or refractory multiple myeloma. Blood. 2017;130(8):974-81.

9. Agarwal A, Chow E, Bhutani M, Voorhees PM, Friend R, Usmani SZ. Practical Considerations in Managing Relapsed Multiple Myeloma. Clinical lymphoma myeloma leukemia. 2017;17(2):69-77.

10. Gajraj E, Chung H, Boysen M, Barnett DB, Longson C. Lenalidomide for the treatment of relapsed multiple myeloma. The Lancet Oncology. 2009;10(7):647-8.

11. Das M. Lenalidomide plus dexamethasone in multiple myeloma. The Lancet Oncology. 2018;19(1):e12.

12. Dimopoulos M, Spencer A, Attal M, Prince HM, Harousseau JL, Dmoszynska A, et al. Lenalidomide plus dexamethasone for relapsed or refractory multiple myeloma. $\mathrm{N}$ Engl $\mathrm{J}$ Med. 2007;357(21):2123-32.

13. Lonial S, Dimopoulos M, Palumbo A, White D, Grosicki S, Spicka I, et al. Elotuzumab Therapy for Relapsed or Refractory Multiple Myeloma. N Engl J Med. 2015;373(7):621-31.

14. Stewart AK, Rajkumar SV, Dimopoulos MA, Masszi T, Spicka I, Oriol A, et al. Carfilzomib, lenalidomide, and dexamethasone for relapsed multiple myeloma. N Engl J Med. 2015;372(2):142-52. 
15. Moreau P, Masszi T, Grzasko N, Bahlis NJ, Hansson M, Pour L, et al. Oral Ixazomib, Lenalidomide, and Dexamethasone for Multiple Myeloma. N Engl J Med. 2016;374(17):1621-34.

16. Dimopoulos MA, Oriol A, Nahi H, San-Miguel J, Bahlis NJ, Usmani SZ, et al. Daratumumab, Lenalidomide, and Dexamethasone for Multiple Myeloma. N Engl J Med. 2016;375(14):1319-31.

17. Hou J, Jin J, Xu Y, Wu D, Ke X, Zhou D, et al. Randomized, double-blind, placebo-controlled phase III study of ixazomib plus lenalidomide-dexamethasone in patients with relapsed/refractory multiple myeloma: China Continuation study. J Hematol Oncol. 2017;10(1):137.

18. Dimopoulos MA, Lonial S, White D, Moreau P, Palumbo A, San-Miguel J, et al. Elotuzumab plus lenalidomide/dexamethasone for relapsed or refractory multiple myeloma: ELOQUENT-2 follow-up and post-hoc analyses on progression-free survival and tumour growth. $\mathrm{Br} \mathrm{J}$ Haematol. 2017;178(6):896-905.

19. Garderet L, lacobelli S, Moreau P, Dib M, Lafon I, Niederwieser D, et al. Superiority of the triple combination of bortezomib-thalidomide-dexamethasone over the dual combination of thalidomidedexamethasone in patients with multiple myeloma progressing or relapsing after autologous transplantation: the MMVAR/IFM 2005-04 Randomized Phase III Trial from the Chronic Leukemia Working Party of the European Group for Blood and Marrow Transplantation. Journal of clinical oncology: official journal of the American Society of Clinical Oncology. 2012;30(20):2475-82.

20. Sun Z, Zheng F, Wu S, Liu Y, Guo H, Liu Y. Triplet versus doublet combination regimens for the treatment of relapsed or refractory multiple myeloma: A meta-analysis of phase III randomized controlled trials. Crit Rev Oncol Hematol. 2017;113:249-55.

21. Botta C, Ciliberto D, Rossi M, Staropoli N, Cuce M, Galeano T, et al. Network meta-analysis of randomized trials in multiple myeloma: efficacy and safety in relapsed/refractory patients. Blood advances. 2017;1(7):455-66.

22. van Beurden-Tan CHY, Franken MG, Blommestein HM, Uyl-de Groot CA, Sonneveld P. Systematic Literature Review and Network Meta-Analysis of Treatment Outcomes in Relapsed and/or Refractory Multiple Myeloma. Journal of clinical oncology: official journal of the American Society of Clinical Oncology. 2017;35(12):1312-9.

23. Dimopoulos MA, Kaufman JL, White D, Cook G, Rizzo M, Xu Y, et al. A Comparison of the Efficacy of Immunomodulatory-containing Regimens in Relapsed/Refractory Multiple Myeloma: A Network Meta-analysis. Clinical lymphoma myeloma leukemia. 2018;18(3):163-73. e6.

24. Wang Y, Yang F, Shen Y, Zhang W, Wang J, Chang VT, et al. Maintenance Therapy With Immunomodulatory Drugs in Multiple Myeloma: A Meta-Analysis and Systematic Review. Journal of the National Cancer Institute. 2016;108(3).

25. Stone CR, Mickle AT, Boyne DJ, Mohamed A, Rabi DM, Brenner DR, et al. Treatment for lymphoma and late cardiovascular disease risk: A systematic review and meta-analysis. Health science reports. 2019;2(10):e135.

26. Jadad AR, Moore RA, Carroll D, Jenkinson C, Reynolds DJ, Gavaghan DJ, et al. Assessing the quality of reports of randomized clinical trials: is blinding necessary? Controlled clinical trials. 1996;17(1):1- 
12.

27. Kimachi M, Furukawa TA, Kimachi K, Goto Y, Fukuma S, Fukuhara S. Direct oral anticoagulants versus warfarin for preventing stroke and systemic embolic events among atrial fibrillation patients with chronic kidney disease. Cochrane Database Syst Rev. 2017;11:CD011373.

28. Raval AD, Thakker D, Rangoonwala AN, Gor D, Walia R. Vitamin B and its derivatives for diabetic kidney disease. Cochrane Database Syst Rev. 2015;1:CD009403.

29. Higgins JP, Thompson SG. Quantifying heterogeneity in a meta-analysis. Statistics in medicine. 2002;21(11):1539-58.

30. Weber DM, Chen C, Niesvizky R, Wang M, Belch A, Stadtmauer EA, et al. Lenalidomide plus dexamethasone for relapsed multiple myeloma in North America. N Engl J Med. 2007;357(21):213342.

31. Sterne JA, Sutton AJ, loannidis JP, Terrin N, Jones DR, Lau J, et al. Recommendations for examining and interpreting funnel plot asymmetry in meta-analyses of randomised controlled trials. Bmj. 2011;343:d4002.

32. Alahmadi M, Masih-Khan E, Atenafu EG, Chen C, Kukreti V, Tiedemann R, et al. Addition of Cyclophosphamide "On Demand" to Lenalidomide and Corticosteroids in Patients With Relapsed/Refractory Multiple Myeloma-A Retrospective Review of a Single-center Experience. Clinical lymphoma myeloma leukemia. 2019;19(4):e195-203.

33. Attal M, Richardson PG, Rajkumar SV, San-Miguel J, Beksac M, Spicka I, et al. Isatuximab plus pomalidomide and low-dose dexamethasone versus pomalidomide and low-dose dexamethasone in patients with relapsed and refractory multiple myeloma (ICARIA-MM): a randomised, multicentre, open-label, phase 3 study. Lancet. 2019;394(10214):2096-107.

34. Richardson PG, San Miguel JF, Moreau P, Hajek R, Dimopoulos MA, Laubach JP, et al. Interpreting clinical trial data in multiple myeloma: translating findings to the real-world setting. Blood cancer journal. 2018;8(11):109.

\section{Figures}




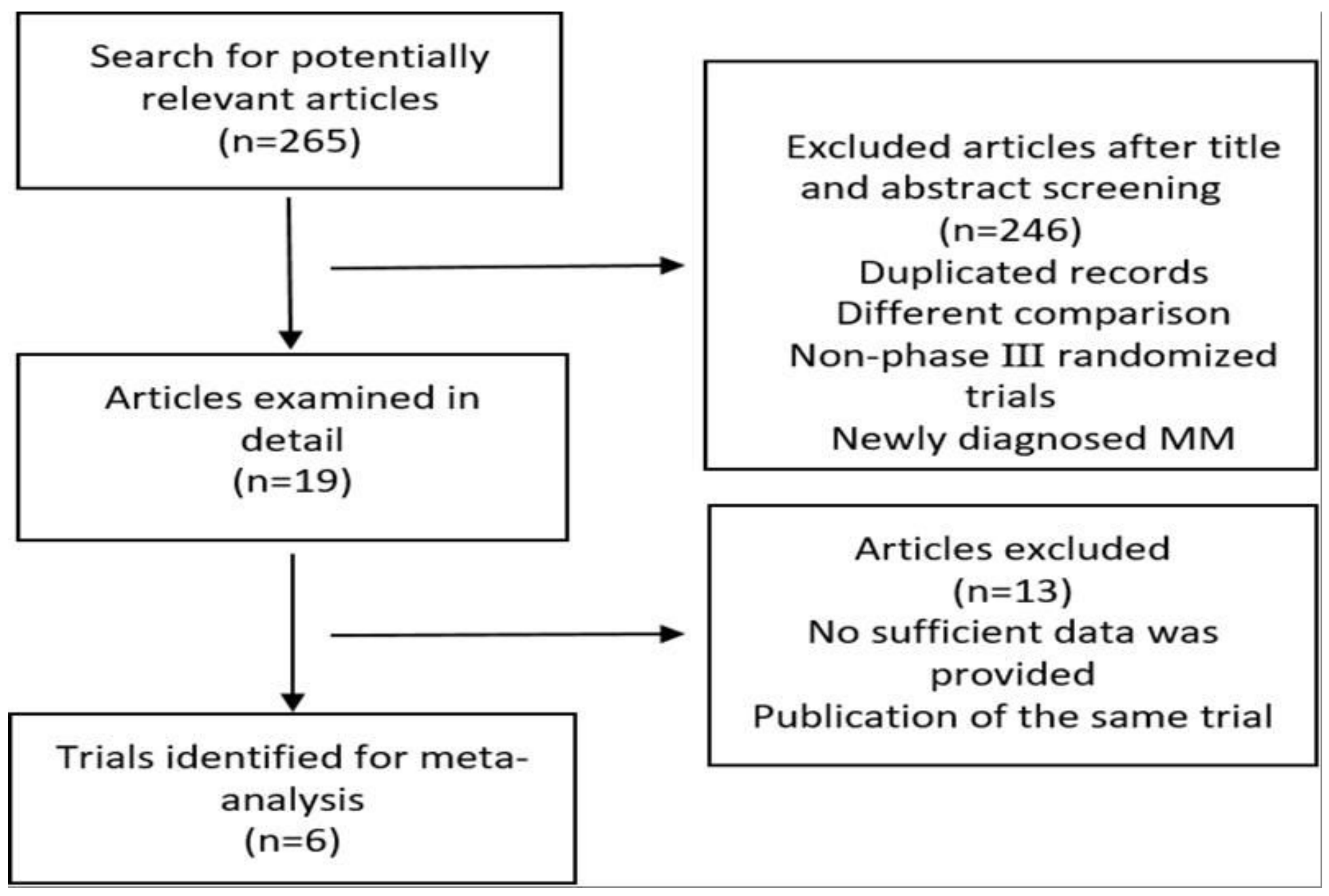

Figure 1

Flowchart diagraming the selection of studies. 
Study ID

$\mathrm{HR}(95 \% \mathrm{Cl})$

$\%$ Weight

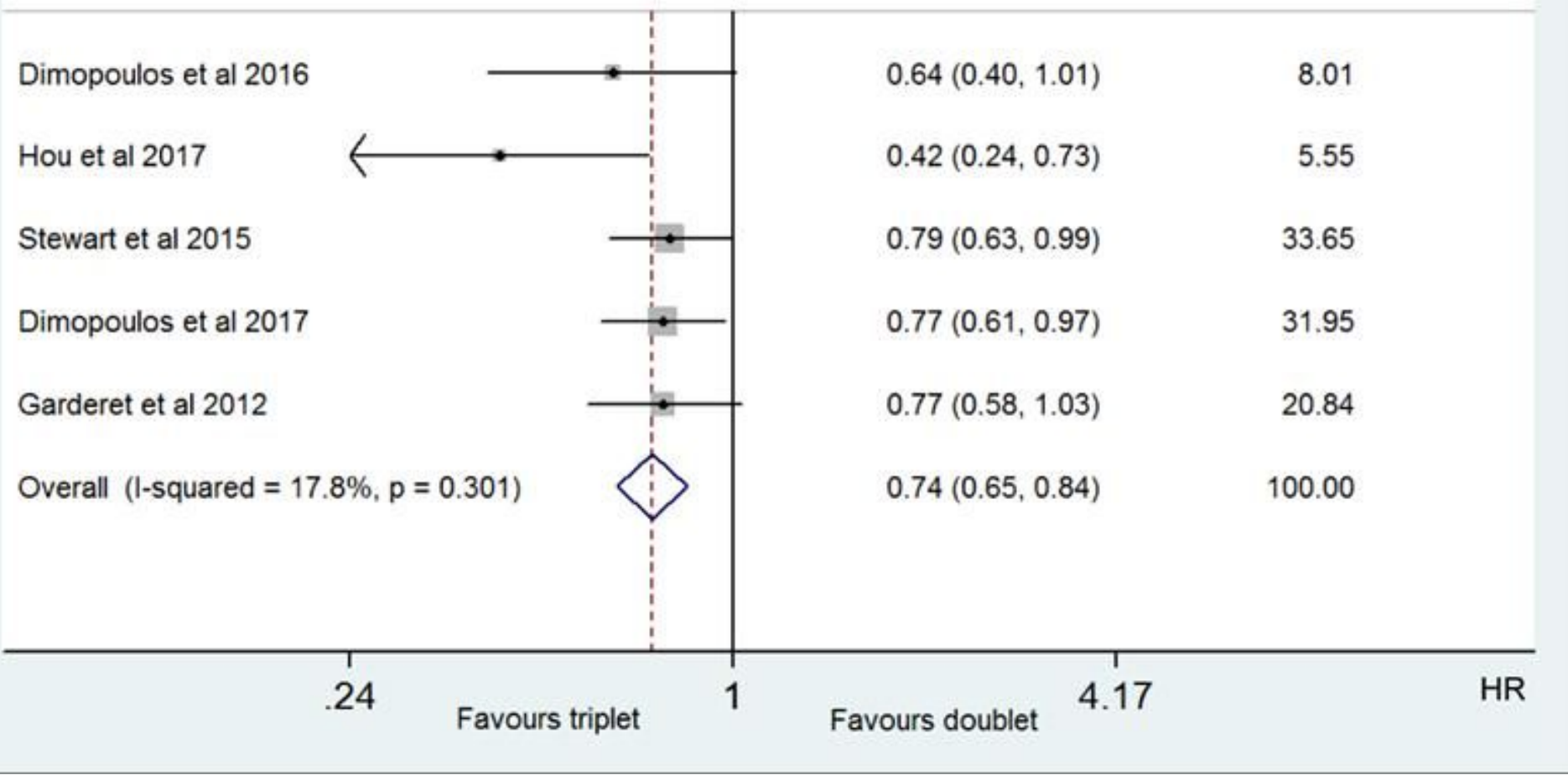

Figure 2

Individual trials and overall hazard ratios for OS associated with immunomodulatory drug and dexamethasone-containing triple combinations versus the doublet combination of an immunomodulatory drug and dexamethasone in RRMM. The horizontal axis represent hazard ratio (HR) and the results are presented on a log scale. Fixed-effects model. 


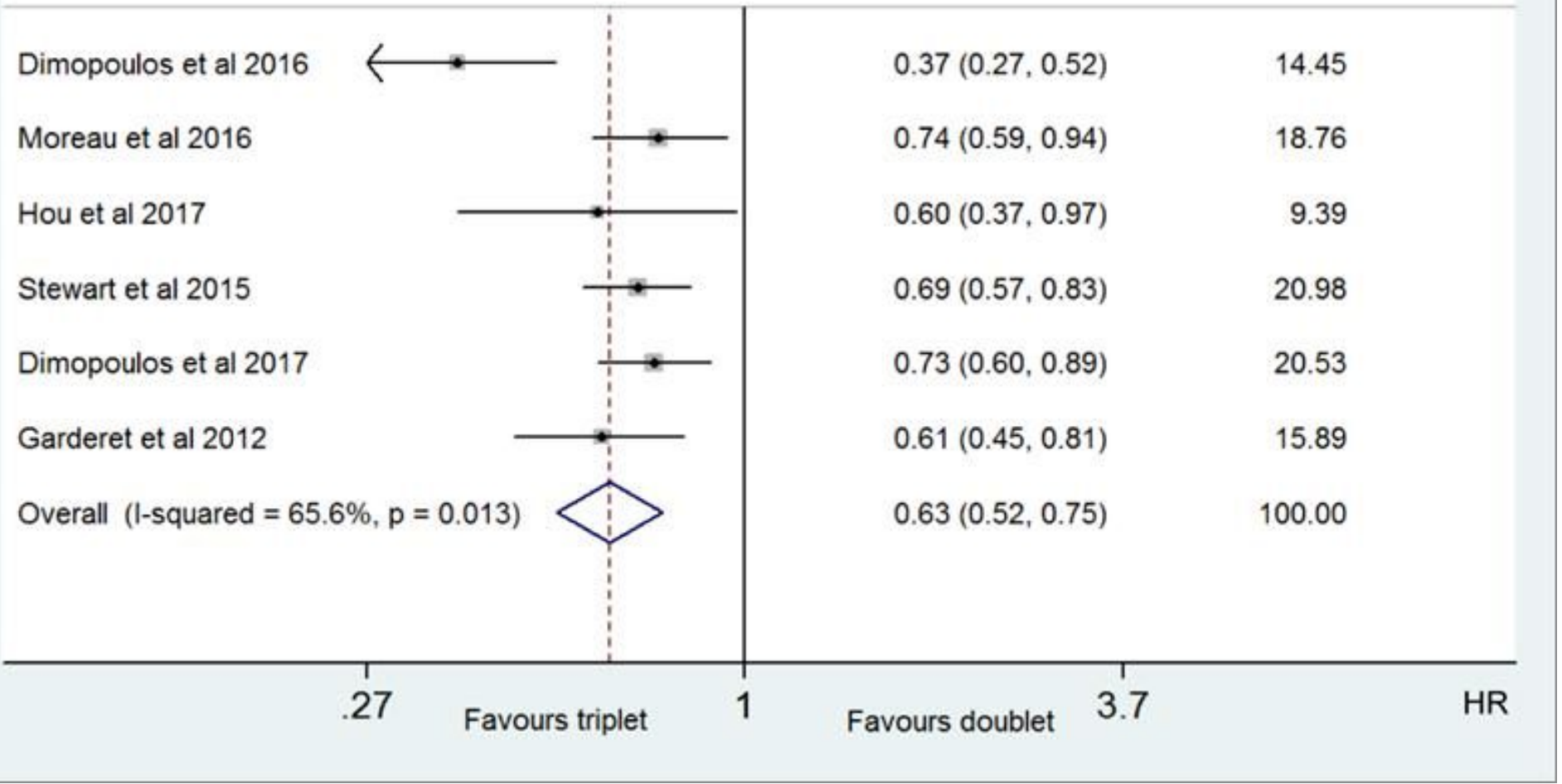

\section{Figure 3}

Individual trials and overall hazard ratios for PFS associated with immunomodulatory drug and dexamethasone-containing triplet therapy versus regimens of only an immunomodulatory drug and dexamethasone in RRMM. The horizontal axis represent hazard ratio (HR) and the results are presented on a log scale. Random-effects model. 
Study

ID

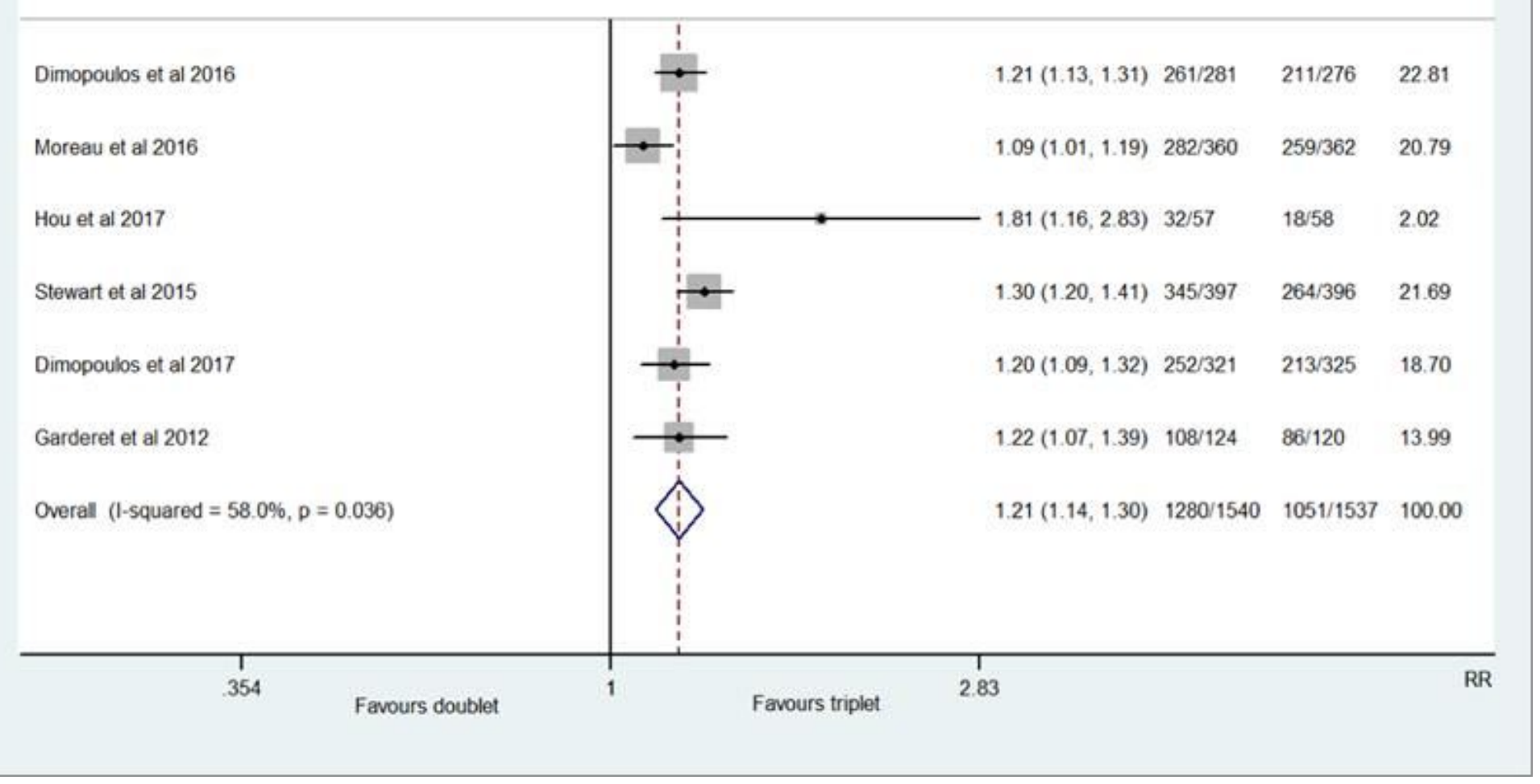

\section{Figure 4}

Individual trials and overall risk ratios for ORR associated with immunomodulatory drug and dexamethasone-containing triple combinations versus a regiment with only an immunomodulatory drug and dexamethasone in RRMM. The horizontal axis represent risk ratio (RR) and the results are presented on a log scale. Random-effects model. 